\title{
Is Tuberculosis Treatment Truly Free? A Study to Identify Key Factors Contributing to the Catastrophic Cost of TB Care in Pakistan
}

\author{
Aamer Ikram ${ }^{1}$, Amna Ali1 ${ }^{*}$, Sana Habib Abbasi ${ }^{1}$, Nosheen Ashraf ${ }^{1}$, Sidra Wali', \\ Mohammad Salman', Mumtaz A. Khan', Naveed Syed'2, Jamil A. Ansari1 \\ ${ }^{1}$ National Institute of Health, Islamabad, Pakistan \\ ${ }^{2}$ Public Health England, London, UK \\ Email:maahin1@yahoo.com, ^amna0409@gmail.com, sana.abbasi20@yahoo.com, nosheenawan@hotmail.com, \\ sidrawali.333@gmail.com, salman14m@gmail.com,drmomi74@hotmail.com, naveed.syed@phe.gov.uk, jam62aa@gmail.com
}

How to cite this paper: Ikram, A., Ali, A., Abbasi, S.H., Ashraf, N., Wali, S., Salman, M., Khan, M.A., Syed, N. and Ansari, J.A. (2020) Is Tuberculosis Treatment Truly Free? A Study to Identify Key Factors Contributing to the Catastrophic Cost of TB Care in Pakistan. Journal of Tuberculosis Research, 8, 181-198.

https://doi.org/10.4236/jtr.2020.84017

Received: August 21, 2020

Accepted: November 2, 2020

Published: November 5, 2020

Copyright $\odot 2020$ by author(s) and Scientific Research Publishing Inc. This work is licensed under the Creative Commons Attribution International License (CC BY 4.0).

http://creativecommons.org/licenses/by/4.0/

\begin{abstract}
Background: The interplay between financial deprivation and tuberculosis (TB) is considered one of the vital socio-economic determinants of disease. This is the first study of its kind to be carried in Pakistan, which aims to identify leading factors contributing towards catastrophic costs of TB diagnosis and management in order to help policy makers. Methodology: From four tertiary care hospitals (TCH) in Islamabad and Rawalpindi, $400 \mathrm{~TB}$ patients were interviewed through a cross-sectional survey. The patient's pre and post-TB income and direct and indirect costs for treatment were analysed following WHO recommendations. Multivariable logistic regression model was used to identify the determinants of catastrophic total cost. Results: For TB management expenditures, the median (interquartile range) of total costs by households was Rs. 58,175 Rs (32,050 - 97,500). At 20\% threshold, $67 \%$ of TB patient's households were affected by catastrophic costs. The determinants of the catastrophic total cost were as follows: patient/guardian employed (adjusted odds ratio $[\mathrm{aOR}]=3.428,95 \%$ confidence interval $[\mathrm{CI}]: 1.900-6.186)$, patient/guardian the only breadwinner $(\mathrm{aOR}=1.751,95 \% \mathrm{CI}: 1.011-3.032)$, follow-up visits at current health facility ( $\mathrm{aOR}=1.352,95 \%$ CI: $1.223-1.494)$, job loss ( $\mathrm{aOR}=3.381,95 \% \mathrm{CI}$ : $1.512-7.561$ ), and unpaid sick leaves ( $\mathrm{aOR}=2.862,95 \% \mathrm{CI}: 1.249-6.558)$. Conclusion: The financial deprivation experienced by patients of low socio-economic status increases as TB treatment proceeds. This negatively impacts the treatment adherence, resulting in poor treatment outcomes due to income and job loss. Outcomes are exacerbated if the family has single breadwinner and treatment requires follow-up visits.
\end{abstract}




\section{Keywords}

Tuberculosis, Financial Deprivation, Catastrophic Cost

\section{Introduction}

Despite numerous attempts to eradicate $\mathrm{TB}$, the disease still poses a serious public health threat, causing an estimated 1.4 million deaths annually [1]. The causative agent for TB is Mycobacterium tuberculosis; responsible for a number of human ailments but principally causes pulmonary disease [2]. The disease is associated with high rates of mortality and morbidity and consequently has a burdensome economic effect on the patients' households [3] [4]. The most prevalent age group globally affected by TB ranges from 15 to 54 years of age, which is the most economically active segment of the population [5] [6]. The World Health Organization-Eastern Mediterranean Region (WHO-EMRO) shoulders 7\% of global TB burden, of which Pakistan alone is responsible for $61 \%$ of cases [7]. With an estimated 510,000 cases every year, Pakistan is ranked $5^{\text {th }}$ out of the 22 most highly burdened countries [6] [7]. Due to poor awareness regarding the disease, patients usually delay treatment, transmitting the infection to an additional 5 to 15 persons [8].

Catastrophic cost is defined as the total cost incurred by a TB-affected household for TB care (direct or indirect) exceeding $20 \%$ of the annual total household income [9] [10]. Globally, more than 150 million people are pushed into poverty annually due to direct payment for health services [11] [12]. Loss of income and transportation cost to healthcare facilities are among the hidden costs associated with free treatment programs. The contribution of these factors to the catastrophic costs and their potential impact on TB-affected households is ill defined and requires more research. In some studies, the largest financial risk for TB patients has been attributed to income loss [13] [14]. Apart from ensuring that healthcare services are properly financed and delivered in a way that reduces direct and indirect costs, there is a need to ensure that $\mathrm{TB}$ patients and affected families receive appropriate income replacement and other social interventions [15]. WHO recommends that the National TB Programs (NTP) lower patient costs associated with TB care through service reorganization among others [16].

Through the introduction of universal health coverage (UHC) concept, WHO aims to highlight the need for access to services at an affordable cost to protect households from catastrophic health expenditures [12]. Many TB-affected households face immensely high indirect costs, which hampers treatment access and creates a risk of financial burden that can lead to further impoverishment [16] [17]. One of the three goals of the end TB strategy (2016-2035) is to prevent catastrophic costs for all the affected households [12] [18]. This target is a fundamental form of financial risk protection and a symbol for progress toward the achievement of universal health coverage. 
In Pakistan, TB medication and treatment are free, but the hidden costs incurred by patients and their families can worsen their poverty. Social protection has recently emerged as a key policy area for TB care and prevention [19] [20]. This also includes the compensation for lost income. Examples of social protection include paid sick leave, disability grants, food and nutritional assistance, travel vouchers, and other support packages [20] [21]. A study from Colombia highlights the importance of paid sick leave as a form of social protection for employees, the absence of which results in financial catastrophe [22].

In our study, we aimed to identify and to assess the leading factors contributing to the catastrophic costs of TB diagnosis and management, to identify the resultant, most prevalent factor contributing to the catastrophic costs of TB care, and to provide recommendations to improve TB outcomes. This study is the first of its kind to be carried out in Pakistan in the hope that it will provide policy makers with an understanding of the factors that adversely impact TB outcomes. Hence, the findings can be used to formulate policies to improve the living standards of TB patients and their families and to reduce the economic burden of the disease and the hidden costs associated with it, thus improving treatment outcomes.

\section{Methodology}

A cross-sectional survey was carried out. Conventional sampling technique was adopted following the WHO recommendations to assess the catastrophic total cost due to TB. Each patient's pre- and post-TB income and direct and indirect costs of TB treatment were analyzed in the study.

The sample size was calculated via a STEPS sample size calculator spreadsheet provided by WHO [23]. The required sample size was $400 \mathrm{~TB}$ patients, which were interviewed from four tertiary care hospitals (TCH) in Islamabad and Rawalpindi linked with the National TB Control Program, which patients visit from all over Pakistan.

$$
\begin{aligned}
n= & \text { Level of Confidence Measure } *(\text { Baseline levels of the indicators } \\
& *(1-\text { Baseline levels of the indicators })) / \text { Margin of Error }(\mathrm{MOE}) \\
& * \text { Margin of Error }(\mathrm{MOE})
\end{aligned}
$$

$n=$ sample size.

Level of Confidence Measure = Describes the level of uncertainty in the sample mean or prevalence as an estimate of the population mean or prevalence.

Margin of Error $(\mathrm{MOE})=$ the expected half-width of the confidence interval. The smaller the margin of error, the larger the sample size needed.

Baseline levels of the indicators $=$ the estimated prevalence of the risk factors within the target population. Values closest to $50 \%$ are the most conservative.

Design effect (Deff) = Describes the loss of sampling efficiency due to using a complex sample design. A value of 1.0 is appropriate for simple random samples.

The health care providers working at the TB care units within these TCH were 
trained to interview the patients. For patients aged less than 15 years, their guardians were interviewed. The study participants were provided with a consent form. For participants who could not read, the trained health care provider read the consent form out loud, after which it was signed by the patient in the presence of a witness. All types of costs related to TB care, diagnostics, and treatment were recorded according to data provided by each patient or guardian [24] [25].

\subsection{Inclusion Criteria}

The inclusion criteria for the patients in this study were as follows:

- Treatment duration of at least one month.

- Treatment completion no more than one month.

- TB diagnosis at least three months previously and active treatment [18].

\subsection{Exclusion Criteria}

- Extra-pulmonary TB and MDR-TB patients.

- Patients suffering from AIDS, hepatitis, and diabetes.

\subsection{Direct and Indirect Costs}

Two types of costs were recorded and analyzed: direct and indirect costs. The direct costs included payment after any reimbursement for medical fees, administration or registration fees, and all diagnostic tests performed pre- or post-diagnosis. In Pakistan, there is usually one earner in most households, so we categorized the patients into single-earner and multiple-earner households.

The indirect costs include special dietary purchases like fruit, milk, meat, and food supplements consumed during the TB treatment, travel costs per visit to the health care facility for TB treatment [10], and loss of income. The changes in the expenditures of patients/guardians after TB diagnosis were estimated. To calculate the costs per month, we multiplied the costs with the number of visits per month to the TB care facility. To estimate the total expenditures of patients/guardians who were working for daily wages or performing informal jobs for which the income is uncertain, we applied the time loss valuation by multiplying their hourly/daily wage by the number of working hours lost due to TB [26].

\subsection{Catastrophic Total Costs}

WHO uses two basic approaches to measure the catastrophic total cost. First, the total costs (direct and indirect) incurred by the household in excess of $20 \%$ of the annual household income are noted. The second approach used by WHO is defined as the share of TB patients who are unable to accumulate savings because they must sell property and livestock or take out a loan to cover costs incurred due to TB [18] [26]. Using the first approach, we calculated the mean gap (G) and the mean positive gap (MPG). The mean gap (G) shows the average payments that exceed the threshold as a proportion of household income. The mean positive gap (MPG) is equal to $\mathrm{G} / \mathrm{H}$ ( $\mathrm{H}$ being the headcount). Using this technique, 
it is possible to identify how severe the total costs are by illustrating the excessive expenditure per household that has experienced catastrophic total costs [25] [27].

Total costs due to TB were defined as the sum of the OOPs incurred for medical diagnosis and treatment (OOPM), OOPs for non-medical expenditures related to the use of TB care services (OOPNM), and patients' and guardians' reported income loss or time loss valuations minus the net of any government treatment allowances. The denominator produced the annual household income in the year before being diagnosed with TB [20] [28] [29].

$$
I=\frac{1}{n} \sum 1\left(\sum \text { OOPM }+ \text { OOPMN }+ \text { Income loss }- \text { Gov allownce }\right) / y>t
$$

\subsection{Data Analysis}

Data analysis was performed using SPSS, and Microsoft Excel was used for graphical representation. The categorical variables are shown as numbers and percentages (\%), whereas abnormally distributed data is shown as median (inter-quartile range [IQR] q25-q75). Binary logistic regression was used to analyse the determinants that affect the catastrophic total costs to the households of TB patients. The significance $(\mathrm{P})$ and the crude odds ratios (cORs) were also estimated in the univariate analysis with $95 \%$ confidence intervals (CIs). All the variables under the above mentioned conditions with a $\mathrm{P}<0.05$ were included in a multivariable analysis to estimate significance and identify the best model, adjusted ORs (aORs), and 95\% CIs.

\subsection{Ethical Permission}

Ethical approval was obtained from the Institutional Review Board (IRB) of the National Institute of Health (NIH), Pakistan. Official permissions were also obtained from the tertiary care hospitals where the study was conducted. An informed consent form was signed by all patients or patient guardians before the interview, which was explained to them verbally, and a copy of the form was given to each patient [19].

\section{Results}

\subsection{Patient Characteristics}

The sample size for this study was 400 TB patients (100 from each of four tertiary care hospitals (TCH) in Rawalpindi and Islamabad) (Map 1), out of which 187 (47\%) were males. Most of the TB patients belonged to the most economically active age group (15 - 34 years), accounting for a total of 202 (51\%) TB cases. Most of the patients lived in poor households with an average (median) monthly income of Rs. 15,500 before TB diagnosis and an IQR of Rs. 10,000 25,500 . Of the working TB patients, 66 (37\%) were working for daily wages or performing informal jobs like driving a cab. The total number of patients or patient guardians who were employed and did not receive paid sick leave was 367 (92\%). A total of 68 (17\%) employed TB patients lost their job after TB diagno- 
sis, whereas $64(16 \%)$ of the TB cases had health insurance and therefore received support for health care costs.

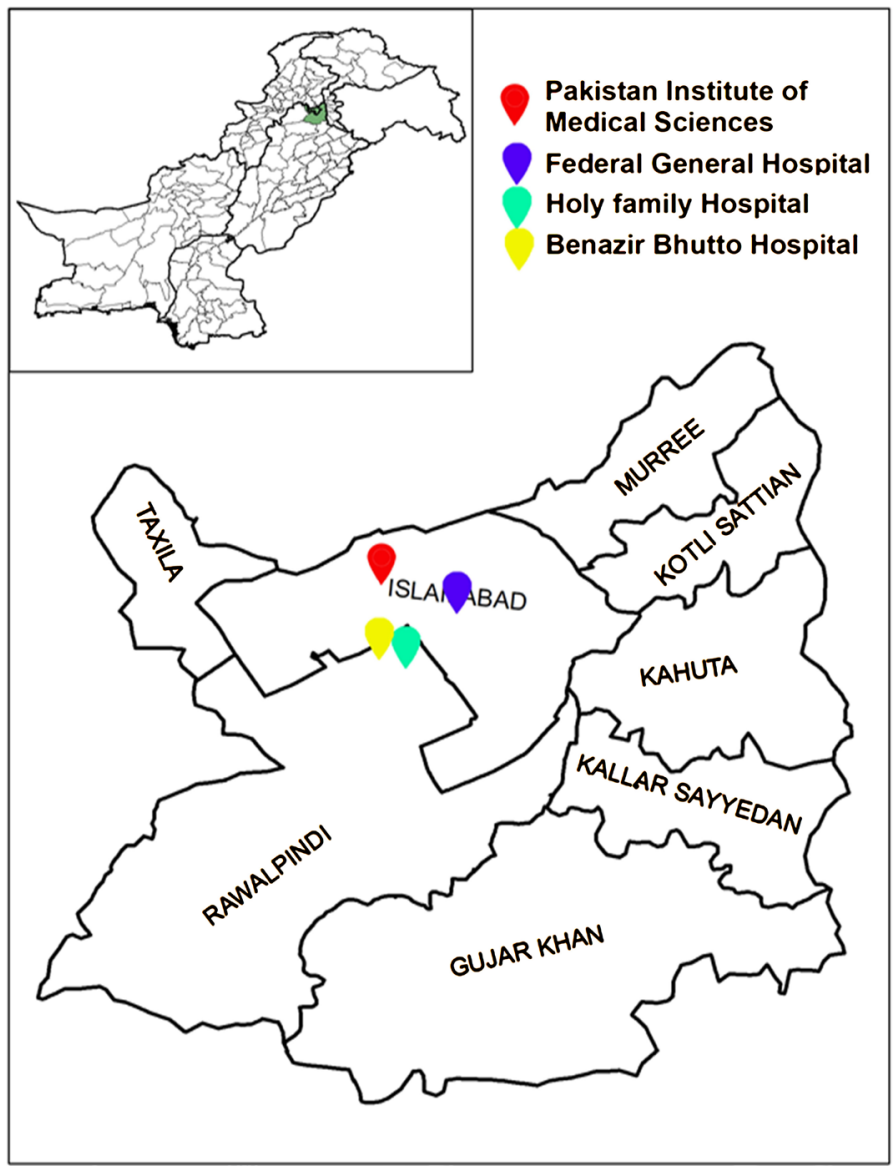

Map 1. Geographical mapping of study area.

Our results show that although public health care facilities are available, a high percentage $(219$, or $55 \%)$ of the patients first went to a private health care centre. The transfer of TB infection between family members took place in 94 (23\%) of the cases. According to this study, 171 (43\%) and 147 (37\%) of the patients or their guardians compensated for their income loss by working over-time/taking a part-time job or by taking a loan, respectively. According to our results, the most common social effects were food insecurity and social exclusion (Figure 1) (Table 1).

\subsection{TB-Related Total Costs}

The median TB related total cost was Rs. 58,175 (IQR: Rs. 32,050 - Rs. 97,500) (Table 2), the median out-of-pocket medical (OOPM) expenditure on TB was Rs. 3100 (IQR: Rs. 300 - Rs. 6000) (Figure 2), the median out-of-pocket non-medical (OOPNM) expenditure on TB was Rs. 17,100 (IQR: Rs. 9150 - Rs. 28,400 ) (Figure 3), and the median income loss of patients/guardians due to TB was Rs. 33,000 (IQR: Rs. 16,500 - Rs. 49,500) (Figure 4). The OOPNM were 29\% 


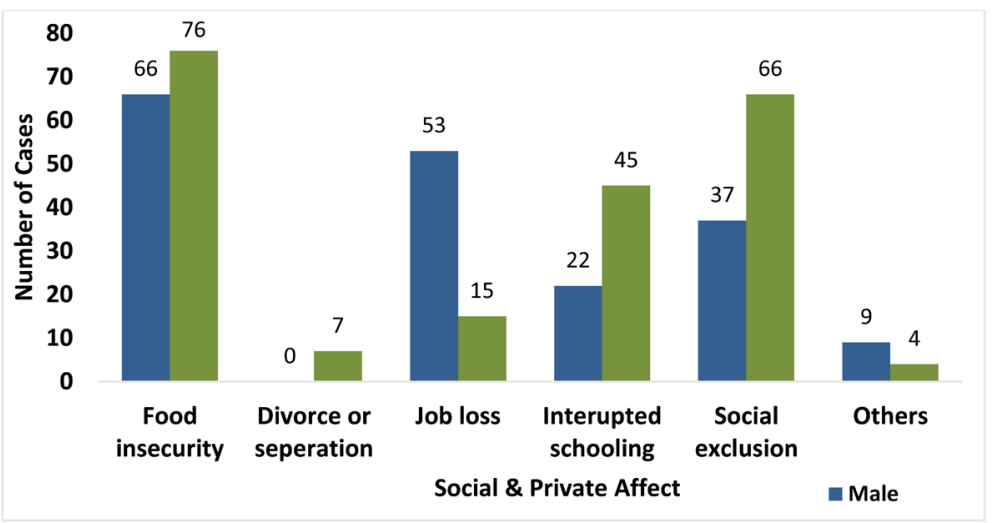

Figure 1. Gender and social/private effects distribution of TB patients.

Table 1. Patient characteristics.

\begin{tabular}{lccr}
\hline & Characteristics $(\mathrm{n}=400)$ & Frequency & Percenta \\
\hline Gender & & 47 \\
Male & 187 & 53 \\
Female & 213 &
\end{tabular}

Age in years

$\begin{array}{lcc}\leq 14 & 27 & 7 \\ 15-34 & 202 & 51 \\ 35-54 & 102 & 25 \\ \geq 55 & 69 & 17\end{array}$

Diagnosis

3 months ago $\quad 194 \quad 49$

4 - 6 months ago $\quad 104 \quad 26$

$\begin{array}{lll}7 \text { - } 9 \text { months ago } & 59 & 15\end{array}$

10 - 12 months ago $\quad 43 \quad 10$

Treatment

$\begin{array}{lcc}3 \text { months ago } & 219 & 55 \\ 4-6 \text { months ago } & 101 & 25 \\ 7 \text { - } 9 \text { months ago } & 47 & 12 \\ 10-12 \text { months ago } & 33 & 8\end{array}$

Income earning job (Household) before TB treatment

Yes

$320 \quad 80$

No

$80 \quad 20$

Patient's Employment Status

Business/Self-employed

$\mathrm{n}=179$

Daily Wages/Informal jobs

$33 \quad 18$

Gov. employee

$66 \quad 37$

Pvt. Employee

$25 \quad 14$

$55-31$ 
Continued

Patient's Unemployment Status

Homemaker

Retired

Student

Unemployed

Single Income at present (patient/guardian)

Yes

No

Monthly Income Before TB

$\leq$ Rs. 10,000

Rs. 11,000 - Rs. 20,000

Rs. 21,000 - Rs. 30,000

>Rs. 30,000

Monthly Income After TB

$\leq$ Rs. 10,000

Rs. 11,000 - Rs. 20,000

Rs. 21,000 - Rs. 30,000

>Rs. 30,000

No. of Dependents

$\leq 5$

$6-10$

$>10$

First Treatment facility visited for treatment

$\begin{array}{lcc}\text { Dispensary } & 62 & 15 \\ \text { Healthcare centre } & 219 & 55 \\ \text { Herbalist/Homeopath } & 22 & 6 \\ \text { Pharmacy } & 19 & 5 \\ \text { Private Hospital } & 78 & 19\end{array}$

Free Diagnostic Tests

Yes

No

190

Free TB Drugs

Yes

No

348

52

Symptom Relieving Drugs

Yes

335

No
65
47

87

13

84

25

6

29

40

75

25

21

55

14

10

30

50

12

8

10

68

22

15

5

5

9

3

16 


\section{Continued}

TB infection Transfer between Family member

Yes

Having Health Insurance

Yes

No

Insurance Type

Donor

Gov. Medical Allowance

Private Health Insurance

Reimbursement Scheme

Gov. Treatment Allowance

Yes

No

Paid Sick Leaves

Yes

No

Loss of Job

Yes

No

Coping with TB care expenditure

Loan

Over Time/Part Time Job

Selling Household Goods

Others

Financial Support

Brother

Children

Husband

Parents

Relatives

\section{Social \& Private Effect}

Divorce or Separation

Food/Nutritional Insecurity

Interrupted Schooling

Job Loss

Social Exclusion

Others
64

336

16

84

$n=64$

50

78

8

12

5

5

$\mathrm{n}=400$

8

2

392

98

33

8

367

92

68

17

332

83

$147 \quad 37$

171

45

43

11

37

9

131

33

49

17

46

11

106

27

68

12

7

2

$142 \quad 35$

$67 \quad 17$

$68 \quad 17$

$103 \quad 26$

$13 \quad 3$ 
Table 2. Characteristics of TB patients and TB related costs with median and (IQR).

\begin{tabular}{|c|c|c|}
\hline Characteristics/Costs & Median & IQR \\
\hline Age & 30 years & $(22-49.50)$ years \\
\hline Male & 33 years & $(23-50)$ years \\
\hline Female & 28 years & $(20-45)$ years \\
\hline Monthly income before TB & Rs. 15,500 & Rs. $(10,000-25,500)$ \\
\hline Monthly income after TB & Rs. 15,000 & Rs. $(5500-15,500)$ \\
\hline Treatment duration at first contact facility & 2 days & $(2-4)$ days \\
\hline Follow up visits at current health facility & 5 & $(3-8)$ \\
\hline Monthly income loss & Rs. 5500 & Rs. $(5000-15,500)$ \\
\hline Treatment duration of TB & 3 months & $(2-6)$ months \\
\hline Cost at diagnostic tests & Rs. 1000 & Rs. $(0$ - 3000) \\
\hline Cost at TB drugs & Rs. 0 & Rs. $(0-0)$ \\
\hline Expenditure at symptom relieving drugs & Rs. 250 & Rs. $(100-500)$ \\
\hline Doctor's fee & Rs. 0 & Rs. $(0-0)$ \\
\hline Travelling cost during treatment & Rs. 2400 & Rs. $(1500-4800)$ \\
\hline Expenditure at special diet during treatment & Rs. 15,000 & Rs. $(7500-22,500)$ \\
\hline Amount Gov. allowance & Rs. 0 & Rs. $(0-0)$ \\
\hline Total costs & Rs. 58,175 & Rs. $(32,050-97,500)$ \\
\hline
\end{tabular}

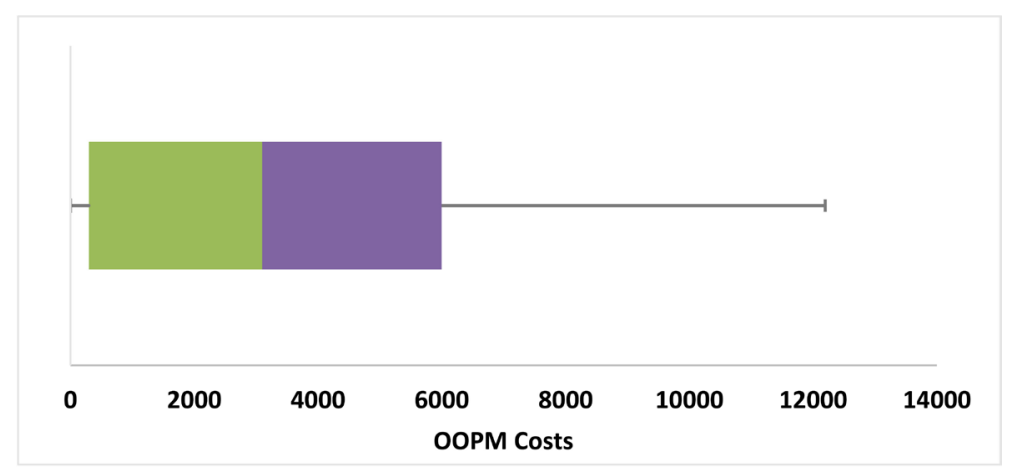

Figure 2. Distribution of OOPM expenditures incurred during TB treatment.

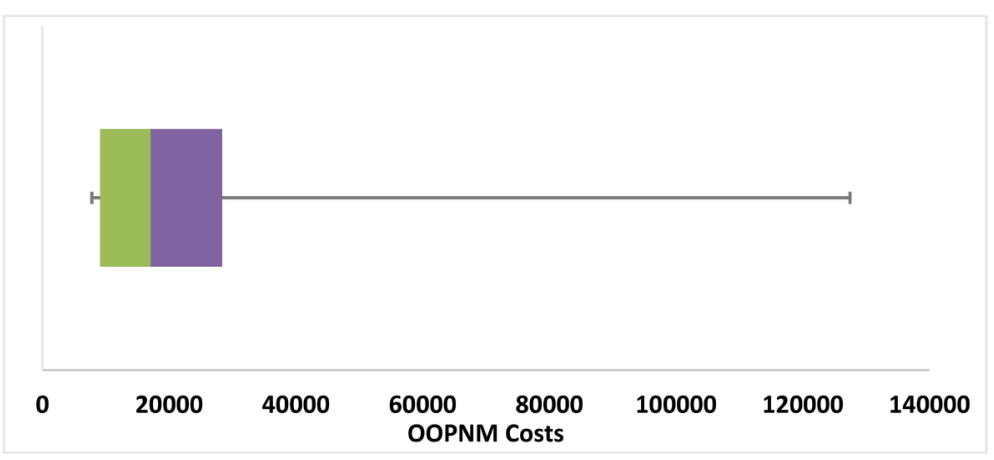

Figure 3. Distribution of OOPNM expenditures incurred during TB treatment. 


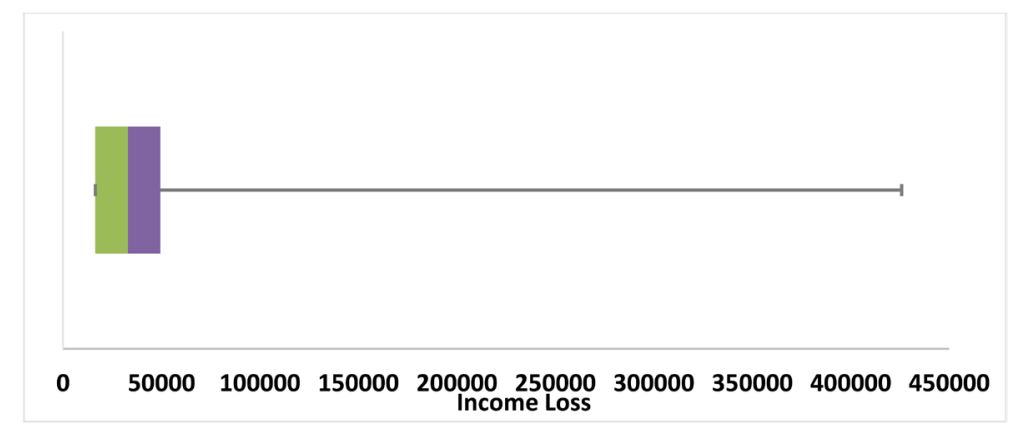

Figure 4. Distribution of income loss due to TB treatment.

of the median total costs, and income loss due to TB was $57 \%$ of the median total costs. Our results show that when the patient lost their job due to TB, they lost a major portion of their income

\subsection{Catastrophic Total Costs}

At the 20\% threshold [17], the incidence (i.e., headcount) of catastrophic total costs was $67 \%$ for the TB patients, with a mean gap $(\mathrm{G})$ of $38 \%$ and a mean positive gap (MPG) of $56 \%$.

\subsection{Determinants of Catastrophic Total Costs}

The multivariate analysis showed that with regard to the catastrophic total cost among TB-affected households, there were five determinants: patient/guardian having an income earning job (i.e., employed (adjusted odds ratio $[\mathrm{aOR}]=$ 3.428, 95\% confidence interval [CI]: $1.900-6.186$; P-value $<0.001$ ), being the only breadwinner of the family $(\mathrm{aOR}=1.751,95 \% \mathrm{CI}: 1.011-3.032, \mathrm{P}$-value $=$ 0.045 ), follow-up visits at the current health care facility $(\mathrm{aOR}=1.352,95 \% \mathrm{CI}$ : 1.223 - 1.494, P-value < 0.001), job loss due to TB ( $\mathrm{aOR}=3.381,95 \% \mathrm{CI}: 1.512$ 7.561, P-value $=0.003)$, and lack of paid sick leave $(\mathrm{aOR}=2.862,95 \% \mathrm{CI}: 1.249$ $6.558, \mathrm{P}$-value $=0.013)($ Table 3$)$ (Figure 5$)$. Lack of a government treatment allowance or lack of health insurance were not determinants of the total catastrophic costs for TB-affected households.

\section{Discussion}

Despite the provision of free treatment, the economic burden faced by patients continues to rise in TB prevalent countries due to total catastrophic costs [30]. Our results suggest that the same holds true for Pakistan. There were several factors contributing to the total catastrophic costs for TB care in this study. The employment status of the patients or their guardians was threatened due to non-availability of paid sick leaves and an increased number of follow-up visits. This is evident by the differences in the monthly incomes of patients or guardians before and after the diagnosis and treatment commencement. Our results indicate that patients who did not receive paid sick leaves were approximately three times more likely to face catastrophic costs in comparison to patients who did. 
Table 3. Determinants of catastrophic total costs in TB cases.

\begin{tabular}{|c|c|c|c|c|c|c|c|c|}
\hline \multirow{2}{*}{ Determinants } & \multicolumn{4}{|c|}{ Catastrophic Total Costs } & \multirow{2}{*}{ P-value } & \multirow{2}{*}{$\operatorname{COR}(95 \% \mathrm{CI})$} & \multirow{2}{*}{$\mathrm{P}$-value } & \multirow{2}{*}{ aOR $(95 \% \mathrm{CI})$} \\
\hline & Yes & $\%$ & No & $\%$ & & & & \\
\hline \multicolumn{9}{|l|}{ Gender } \\
\hline Male & 129 & 69 & 58 & 31 & & 1 & & \\
\hline Female & 139 & 65 & 74 & 35 & 0.429 & $1.184(0.779-1.800)$ & & \\
\hline \multicolumn{9}{|l|}{ Age in years } \\
\hline$\leq 14$ & 13 & 48 & 14 & 52 & 0.038 & $0.379(0.152-0.948)$ & & \\
\hline $15-34$ & 132 & 65 & 70 & 35 & 0.389 & $0.770(0.424-1.396)$ & & \\
\hline $35-54$ & 74 & 73 & 28 & 27 & 0.827 & $1.079(0.548-2.125)$ & & \\
\hline$\geq 55$ & 49 & 71 & 20 & 29 & & 1 & & \\
\hline \multicolumn{9}{|c|}{ Income earning job (Household) before TB treatment } \\
\hline Yes & 236 & 74 & 84 & 26 & $<0.001$ & $4.214(2.526-7.032)$ & $<0.001$ & $3.428(1.900-6.186)$ \\
\hline No & 32 & 40 & 48 & 60 & & 1 & & 1 \\
\hline \multicolumn{9}{|l|}{ Single Income at present } \\
\hline Yes & 214 & 72 & 84 & 28 & 0.001 & $2.365(1.425-3.600)$ & 0.045 & $1.751(1.011-3.032)$ \\
\hline No & 54 & 53 & 48 & 47 & & 1 & & 1 \\
\hline \multicolumn{9}{|l|}{ Monthly Income Before TB } \\
\hline$\leq$ Rs. 10,000 & 87 & 100 & 0 & 0 & 0.996 & 3634 & & \\
\hline Rs. 11,000 - Rs. 20,000 & 146 & 69 & 73 & 33 & $<0.001$ & $4.500(2.156-9.392)$ & & \\
\hline Rs. 21,000 - Rs. 30,000 & 23 & 42 & 32 & 58 & 0.276 & $1.617(0.680-3.844)$ & & \\
\hline$>$ Rs. 30,000 & 12 & 31 & 27 & 69 & & 1 & & \\
\hline \multicolumn{9}{|l|}{ Highest income earner before TB } \\
\hline Yes & 80 & 63 & 46 & 37 & 0.312 & $0.796(0.511-1.240)$ & & \\
\hline No & 188 & 69 & 86 & 31 & & 1 & & \\
\hline \multicolumn{9}{|l|}{ Free Diagnostic Tests } \\
\hline Yes & 139 & 66 & 71 & 34 & & 1 & & \\
\hline No & 129 & 68 & 61 & 32 & 0.717 & $1.080(0.711-1.640)$ & & \\
\hline \multicolumn{9}{|l|}{ Free TB Drugs } \\
\hline Yes & 241 & 69 & 107 & 31 & & 1 & & 1 \\
\hline No & 27 & 52 & 25 & 48 & 0.015 & $0.480(0.266-0.865)$ & 0.999 & $0(0 \ldots)$ \\
\hline Follow up visits at current health facility & 268 & 67 & 132 & 33 & $<0.001$ & $1.324(1.212-1.447)$ & $<0.001$ & $1.352(1.223-1.494)$ \\
\hline \multicolumn{9}{|l|}{ Symptom Relieving Drugs } \\
\hline Yes & 225 & 67 & 110 & 33 & 0.874 & $1.047(0.597-1.836)$ & & \\
\hline No & 43 & 66 & 22 & 34 & & 1 & & \\
\hline \multicolumn{9}{|l|}{ TB Infection Transfer between Family } \\
\hline Yes & 64 & 68 & 30 & 32 & 0.798 & $1.067(0.651-1.749)$ & & \\
\hline No & 204 & 67 & 102 & 33 & & 1 & & \\
\hline
\end{tabular}


Continued

Having Health Insurance

$\begin{array}{ccccccc}\text { Yes } & 43 & 67 & 21 & 33 & 0.972 & 1.010(0.572-1.785) \\ \text { No } & 225 & 67 & 111 & 33 & & 1\end{array}$

Gov. Treatment Allowance

$\begin{array}{ccccccc}\text { Yes } & 6 & 67 & 3 & 33 & 0.983 & 0.985(0.242-4.001) \\ \text { No } & 262 & 67 & 129 & 33 & & 1\end{array}$

Paid Sick Leaves

Yes

No

Expenditure on diagnostic tests

$<$ Rs. 5,000

$\geq$ Rs. 5,000

free

Monthly expenditure on TB drugs

$<$ Rs. 5,000

$\geq$ Rs. 5,000

free

Monthly expenditure on special diet

$<$ Rs. 5,000

Rs. 5,000 - Rs. 7,000

Rs. 8,000 - Rs. 10,000

>Rs. 10,000

$\begin{array}{rrrr}16 & 49 & 17 & 51 \\ 252 & 69 & 115 & 31\end{array}$

0.021

$2.328(1.136-4.771)$

$0.013 \quad 2.862(1.249-6.558)$

56

$76 \quad 84$

$\begin{array}{llll}136 & 66 & 70 & 34\end{array}$

$22 \quad 50$

$8 \quad 73$

238

69

$\begin{array}{cc}22 & 50 \\ 3 & 27 \\ 107 & 31\end{array}$

0.013

$0.450(0.239-0.847)$

$1.199(0.312-4.608)$

0.701

$1.408(0.246-8.042)$

1

0.999

$0(0 \ldots)$

\section{Job Loss}

\begin{tabular}{ccccccccc} 
Yes & 58 & 85 & 10 & 15 & 0.001 & $3.413(1.683-6.923)$ & 0.003 & $3.381(1.512-7.561)$ \\
No & 209 & 63 & 123 & 37 & & 1 & 1 \\
\hline
\end{tabular}

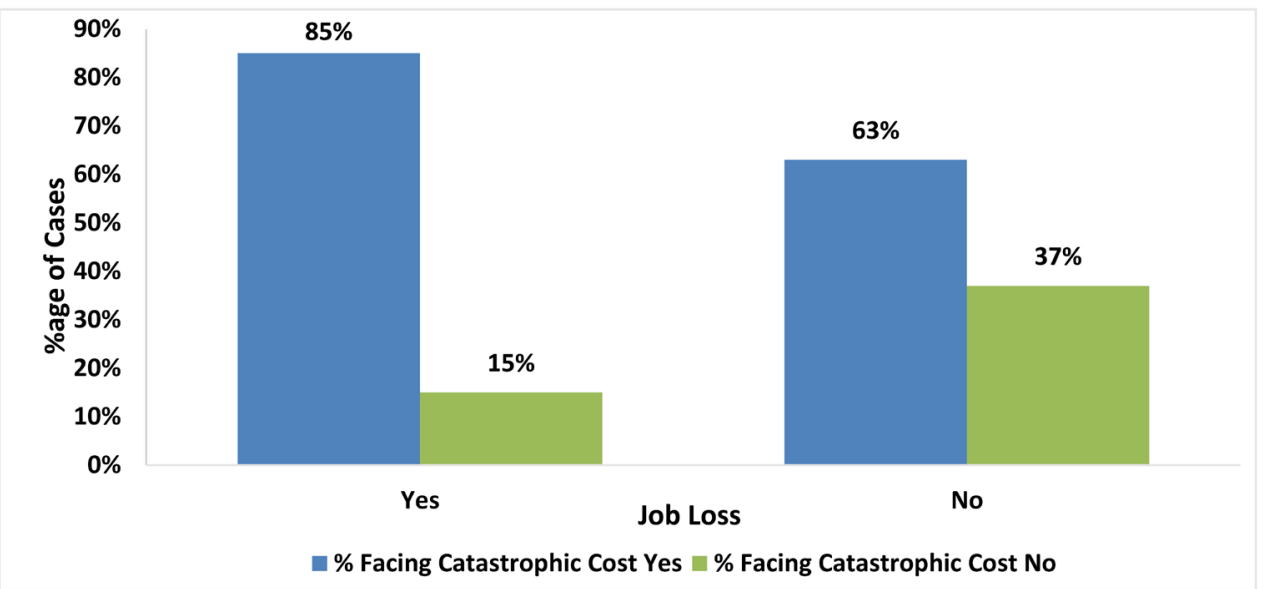

Figure 5. Distribution of TB cases facing catastrophic cost due to employment loss. 
The catastrophic costs faced by informal workers were higher due to daily income loss for the days they were unable to work due to disease or treatment. Similarly, patients or their accompanying guardians who had to go for more follow-up visits to health facility were 1.35 times more likely to be affected by catastrophic costs than those who had fewer follow-up visits due to travel and accommodation costs. A large number of patients from neighboring areas visit Islamabad and Rawalpindi due to the availability of better health care facilities in these cities.

Moreover, households were more likely to be affected when there was a single source of income. Nonetheless, the most important contribution to catastrophic costs was job loss after diagnosis. Our results show that when the patient lost their job due to TB, they lost a major proportion of their income. This indicates the complex dynamics of the interplay between the non-availability of paid sick leave and a high number of follow-up visits, which adversely affect the employment status of the patient or their guardian, with job loss as an ultimate consequence. Thus, job loss becomes the main driver of total catastrophic costs. Our results coincide with studies from Indonesia, which shares a TB burden similar to that of Pakistan, with income and job loss as the main factors contributing to catastrophic costs despite the presence of universal health coverage (UHC) [10] [31].

As per the results of our study, more than half of our sample was facing the dilemma of catastrophic total costs. This indicates that providing free TB drugs covers only a small portion of one of the three pillars of total catastrophic costs; therefore, it is highly overoptimistic to assume that this alone will play a significant role in minimizing said costs. This study highlights how seriously income loss impacts the patient or the patient's guardian, making it an important factor to be considered while formulating national policies in line with the milestones set by the WHO End-TB Strategy [32]. Research suggests that catastrophic costs pose barriers to achieving consistent treatment, thereby causing adherence problems, which leads to poor disease outcomes [33]. The fact that TB is a disease of the poor means there is usually a single source of income in the affected household, in which case job loss has an aggravating impact on not only the patient but also the patient's entire household.

Our findings suggest that the costs of TB drugs and symptom-relieving drugs did not pose any significant financial burden on the patients. These findings are consistent with findings from other countries [34] [35].

There are several limitations to our study. As this study was conducted in government hospitals in only two cities, there is a possible underestimation of the catastrophic costs faced by patients and their households. TB-affected households residing in smaller cities, having lower incomes, and having less formal jobs would be affected more. In addition, patients visiting private health care centers would face more out-of-pocket expenditures than patients being treated at public sector hospitals. Another factor contributing to the underestimation of catastrophic costs is the fact that patients who may have dropped out 
during the treatment phase were not included in the study. The inclusion of MDR-TB patients would also have given us a better idea of the financial catastrophe faced by poor patients. Therefore, although this study can be generalized to two study cities and the neighboring areas, patients from other parts of the country could have different characteristics that require further investigation. Nonetheless, it is fair to assume that the catastrophic costs faced by TB households would only be higher if a national survey was conducted.

Through this study, we aim to provide policy makers with a basis for understanding the impact of catastrophic costs and how TB treatment must go beyond the provision of free drugs in order to reduce disease impact. This is the first study to be conducted in Pakistan to assess the factors contributing to catastrophic costs for TB care in the country, and it provides baseline data about the catastrophic costs that TB-affected households face in Rawalpindi and Islamabad. The primary implication is to strongly recommend that government heads and policy makers introduce fine-tuned healthcare interventions designed to provide social protections to patients and their guardians that go beyond providing free TB drugs, diagnostic tests, and nutritional supplements. This would also include travel and accommodation vouchers for patients visiting healthcare facilities in other cities. These interventions must also alleviate the stigma associated with the disease, which not only plays an important role in income loss but is the driving force behind social exclusion. Furthermore, food insecurity and the factors leading to coping strategies such as taking loans from relatives, selling household items and working overtime, must be addressed as well. It is however, pertinent to understand that one-time cash payment for these factors would not reduce the catastrophic cost to zero percent, the goal set in the WHO End TB Strategy. Therefore, one strategy would be to provide financial support which covers, if not fully, but a part of all these determinants combined. The government can play a pivotal role in mitigating these factors for patients in order to adhere to both the WHO End TB Strategy and the Sustainable Development Goal (SDG) of having zero TB households facing catastrophic costs by the years 2035 and 2030, respectively through financial support of those households in particular which incur catastrophic cost, rather than all the TB-affected households.

\section{Conclusion}

Once patients from low socio-economic class undergo treatment for $\mathrm{TB}$, their risk of facing financial deprivation becomes even more apparent. This results in poor treatment adherence and can therefore worsen the treatment outcomes. These findings suggest an urgent need to provide interventions for patients and their households in order to mitigate the financial catastrophe and improve TB treatment outcomes.

\section{Funding}

This work was supported by WHO-TDR, the Special Programme for Research 
and Training in Tropical Diseases (TDR). TDR is based at the World Health Organization (WHO) and is sponsored by the United Nations Children's Fund (UNICEF), the United Nations Development Programme (UNDP), the World Bank, and WHO.

\section{Conflicts of Interest}

The authors declare no conflicts of interest regarding the publication of this paper.

\section{References}

[1] Wingfield, T., Boccia, D., Tovar, M., Gavino, A., Zevallos, K., Montoya, R., et al. (2014) Defining Catastrophic Costs and comparing Their Importance for Adverse Tuberculosis Outcome with Multi-Drug Resistance: A Prospective Cohort Study, Peru. PLoS Medicine, 11, e1001675. https://doi.org/10.1371/journal.pmed.1001675

[2] Adigun, R. and Singh, R. (2019) Tuberculosis. StatPearls Publishing, Treasure Island. https://www.ncbi.nlm.nih.gov/books/NBK441916/

[3] Glaziou, P., Sismanidis, C., Floyd, K. and Raviglione, M. (2014) Global Epidemiology of Tuberculosis. Cold Spring Harbor Perspectives in Medicine, 5, a017798. https://doi.org/10.1101/cshperspect.a017798

[4] WHO (2019) Tuberculosis. Key Facts. https://www.who.int/news-room/fact-sheets/detail/tuberculosis

[5] WHO (2019) Countries-Pakistan. Tuberculosis. http://www.emro.who.int/pak/programmes/stop-tuberculosis.html

[6] Ejaz, M., Siddiqui, A.R., Rafiq, Y., Malik, F., Channa, A., Mangi, R., et al. (2010) Prevalence of Multi-Drug Resistant Tuberculosis in Karachi, Pakistan: Identification of at Risk Groups. Transactions of the Royal Society of Tropical Medicine and Hygiene, 104, 511-517. https://doi.org/10.1016/j.trstmh.2010.03.005

[7] Bonu, S., Bhushan, I., Rani, M. and Anderson, I. (2009) Incidence and Correlates of "Catastrophic" Maternal Health Care Expenditure in India. Health Policy and Planning, 24, 445-456. https://doi.org/10.1093/heapol/czp032

[8] Fuady, A., Houweling, T.A.J., Mansyur, M. and Richardus, J.H. (2018) Catastrophic Total Costs in Tuberculosis-Affected Households and Their Determinants since Indonesia's implementation of Universal Health Coverage. Infectious Diseases of Poverty, 7, Article No. 3. https://doi.org/10.1186/s40249-017-0382-3

[9] Von Philipsborn, P., Steinbeis, F., Bender, M.E., Regmi, S. and Tinnemann, P. (2015) Poverty-Related and Neglected Diseases-An Economic and Epidemiological Analysis of Poverty Relatedness and Neglect in Research and Development. Global Health Action, 8, Article 25818. https://doi.org/10.3402/gha.v8.25818

[10] Tanimura, T., Jaramillo, E., Weil, D., Raviglione, M. and Lönnroth, K. (2014) Financial Burden for Tuberculosis Patients in Low- and Middle-Income Countries: A Systematic Review. European Respiratory Journal, 43, 1763-1775. https://doi.org/10.1183/09031936.00193413

[11] Qadeer, E., Fatima, R., Yaqoob, A., Tahseen, S., Haq, M.U., Ghafoor, A., et al. (2016) Population Based National Tuberculosis Prevalence Survey among Adults (>15 years) in Pakistan, 2010-2011. PLoS ONE, 11, e0148293. https://doi.org/10.1371/journal.pone.0148293

[12] KNCV Tuberculosis Foundation, WHO and the Japan Anti-Tuberculosis Associa- 
tion (2009) The Tool to Estimate Patients' Costs. Tuberculosis Coalition for Technical Assistance, US Agency for International Development, Washington DC, 1-3.

[13] Viney, K., Islam, T., Hoa, N.B., Morishita, F. and Lönnroth, K. (2019) The Financial Burden of Tuberculosis for Patients in the Western-Pacific Region. Tropical Medicine Infectious Disease, 4, 94. https://doi.org/10.3390/tropicalmed4020094

[14] Barter, D.M., Agboola, S.O., Murray, M.B. and Barnighausen, T. (2012) Tuberculosis and Poverty: The Contribution of Patient Costs in Sub-Saharan Africa-A Systematic Review. BMC Public Health, 12, Article No. 980. https://doi.org/10.1186/1471-2458-12-980

[15] Raviglione, M. and Sulis, G. (2016) Tuberculosis 2015: Burden, Challenges and Strategy for Control and Elimination. Infectious Disease Reports, 8, 6570. https://doi.org/10.4081/idr.2016.6570

[16] O’Donnell, O., Van Doorslaer, E., Wagstaff, A. and Lindelow, M. (2008) Analyzing Health Equity Using Household Survey Data. A Guide to Techniques and Their Implementation. World Bank, Washington DC.

https://doi.org/10.1596/978-0-8213-6933-3

[17] Prasanna, T., Jeyashree, K.,Chinnakali, P., Bahurupi, Y., Vasudevan, K. and Das, M. (2018) Catastrophic Costs of Tuberculosis Care: A Mixed Methods Study from Puducherry, India. Global Health Action, 11, Article ID: 1477493. https://doi.org/10.1080/16549716.2018.1477493

[18] Kirigia, J.M. and Muthuri, R.D. (2016) Productivity Losses Associated with Tuberculosis Deaths in the World Health Organization African Region. Infectious Diseases of Poverty, 5, Article No. 43. https://doi.org/10.1186/s40249-016-0138-5

[19] World Health Organization (2012) Integrating Community-Based Tuberculosis Activities into the Work of Non-Governmental and Other Civil Society Organizations: Operational Guidance. Geneva: World Health Organization, Geneva.

[20] Ukwaja, K.N., Alobu, I., Abimbola, S. and Hopewell, C. (2013) Household Catastrophic Payments for Tuberculosis Care in Nigeria: Incidence, Determinants, and Policy Implications for Universal Health Coverage. Infectious Diseases of Poverty, 2, Article No. 21. https://doi.org/10.1186/2049-9957-2-21

[21] Amaya-Lara, J.L. (2016) Catastrophic Expenditure Due to Out-of-Pocket Health Payments and Its Determinants in Colombian Households. International Journal for Equity in Health, 15, Article No.182. https://doi.org/10.1186/s12939-016-0472-Z

[22] UNCDF and UNDP (2011) Local Government and Social Protection: Making Service Delivery Available for the Most Vulnerable. UN Capital Development Fund and United Nations Development Programme, New York.

[23] Mauch, V., Bonsu, F., Gyapong, M., Awini, E., Suarez, P., Marcelino, B., et al. (2013) Free Tuberculosis Diagnosis and Treatment Are Not Enough: Patient Cost Evidence from Three Continents. The International Journal of Tuberculosis and Lung Disease, 17, 381-387. https://doi.org/10.5588/ijtld.12.0368

[24] https://www.who.int/ncds/surveillance/steps/resources/sampling/en/

[25] World Health Organization (2015) Protocol for Survey to Determine Direct and Indirect Costs Due to TB and to Estimate Proportion of TB-Affected Households Experiencing Catastrophic Total Costs Due to TB. World Health Organization, Geneva.

[26] Mauch, V., Woods, N., Kirubi, B., Kipruto, H., Sitienei, J. and Klinkenberg, E. (2011) Assessing Access Barriers to Tuberculosis Care with the Tool to Estimate Patients' Costs: Pilot Results from Two Districts in Kenya. BMC Public Health, 11, Article No. 43. https://doi.org/10.1186/1471-2458-11-43 
[27] Van Den Hof, S., Collins, D., Hafidz, F., Beyene, D., Tursynbayeva, A. and Tiemersma, E. (2016) The Socioeconomic Impact of Multidrug Resistant Tuberculosis on Patients: Results from Ethiopia, Indonesia and Kazakhstan. BMC Infectious Disease, 16, Article No. 470. https://doi.org/10.1186/s12879-016-1802-X

[28] Tuberculosis Control Assistance Programme (2009) The Tool to Estimate Patients' Costs. The Hague, KNCV Tuberculosis Foundation, Netherlands.

[29] Zhou, C., Long, Q., Chen, J., Xiang, L., Li, Q., Tang, S., et al. (2016) Factors That Determine Catastrophic Expenditure for Tuberculosis Care: A Patient Survey in China. Infectious Diseases of Poverty, 5, Article No. 6. https://doi.org/10.1186/s40249-016-0100-6

[30] Long, Q., Smith, H., Zhang, T.H., Tang, S.L. and Garner, P. (2011) Patient Medical Costs for Tuberculosis Treatment and Impact on Adherence in China: A Systematic Review. BMC Public Health, 11, Article No. 393.

https://doi.org/10.1186/1471-2458-11-393

[31] Fuady, A., Houweling, T.A.J., Mansyur, M., Burhan, E. and Richardus, J.H. (2019) Effect of Financial Support on Reducing the Incidence of Catastrophic Costs among Tuberculosis-Affected Households in Indonesia: Eight Simulated Scenarios. Infectious Diseases of Poverty, 8, Article No. 10. https://doi.org/10.1186/s40249-019-0519-7

[32] World Health Organization (2014) The End TB Strategy: Global Strategy and Targets for Tuberculosis Prevention, Care and Control after 2015. World Health Organization, Geneva.

[33] Tola, H.H., Tol, A., Shojaeizadeh, D. and Garmaroudi, G. (2015) Tuberculosis Treatment Non-Adherence and Lost to Follow Up among TB Patients with or without HIV in Developing Countries: A Systematic Review. Iran J Public Health, 44, 1-11.

[34] Alipanah, N., Jarlsberg, L., Miller, C., Linh, N.N., Falzon, D., Jaramillo. E., et al. (2018) Adherence Interventions and Outcomes of Tuberculosis Treatment: A Systematic Review and Meta-Analysis of Trials and Observational Studies. PLoS Medicine, 15, e1002595. https://doi.org/10.1371/journal.pmed.1002595

[35] Stracker, N., Hanrahan, C., Mmolawa, L., Nonyane, B., Tampi, R., Tucker, A., et al. (2019) Risk Factors for Catastrophic Costs Associated with Tuberculosis in Rural South Africa. International Journal of Tuberculosis and Lung Disease, 23, 756-763. https://doi.org/10.5588/ijtld.18.0519 